\title{
INTEGRATING REFUGEES INTO SOCIETY AND EDUCATION THROUGH LANGUAGE TRAINING: A CASE STUDY IN ORDU, TURKEY
}

\author{
Halis Gözpınar \\ Giresun University, Turkey \\ E-Mail: halisgozpinar@gmail.com
}

\begin{abstract}
This paper approaches addressing the linguistic needs of Iraqi refugee students living in Turkey. Having a command of Turkish and English will allow them to feel more selfconfident, more easily establish communication with their peers, receive better education, have broader employment opportunities, and eventually earn better income. Language will also help remove the distance between them and society, enable healthy dialogue, and speed up their process of social integration. Turkey is trying to find solutions to this language and social barrier. The core of this research is comprised of eighty-three Iraqi refugee students receiving education at a middle, as well as high school, in the province of Ordu. The students' educational progression was evaluated through classroom observation, interviews, e-mails, telephone conversations, face-to-face discussions, family visits, and casual talks with parents, children, youth, and teachers, and then defined as a sample group. The aim of this paper is to show what benefits the foreign language training we provide has on institutions, communities, and individuals, in order to accelerate guest students' adaptation into the society within which they are living, as well as into education. This paper is also expected to serve as a reference guide for language training programs in multicultural environments as is based on the results obtained from our research and experience.
\end{abstract}

Key words: Refugee students, language training, multicultural education

\section{INTRODUCTION}

A June 2016 report by the United Nations High Commissioner for Refugees (UNHCR) notes that there are currently some 65.3 million migrant and/or displaced people worldwide. As of last year, that number has increased by $10 \%$. Upon consideration, this figure is higher than the individual populations of many countries. What is most dramatic is that over half of these migrants are children who have been forced away from their homelands due to emotional and economic reasons and/or lack of security. Today, what first comes to most of our minds (as Turks) when we hear or see the word 'migrant' are persons from Iraq or Syria fleeing war. People however are not only forced to abandon home because of war alone, but also because of natural disasters, violence, and poverty.

It is important to establish appropriate terminology for the benefit of the psychological well-being of Iraqi refugee students in so far that the use of inclusive rather than exclusive language contributes to their sense of belonging within the Turkish school environment. 
According to Article 1 of the 1951 Geneva Convention, the term "refugee" is defined as "owing to well-founded fear of being persecuted for reasons of race, religion, nationality, membership of a particular social group or political opinion, is outside the country of his nationality and is unable or, owing to such fear, is unwilling to avail himself of the protection of that country."

The Regional Refugee and Resilience Plan (3RP) uses the term "resilience" when referring to refugees, in which it defines resilience as "the ability of individuals, households, communities, and institutions to anticipate, withstand, recover and transform from shocks and crises." In the long term, such an approach would aid as well as sooth the psychologies of such individuals. Any person who has arisen from difficulty can extract personal meaning from this word (Luthar \& Cicchetti 2000).

As a report by UNICEF (2016) has expressed, language is "an important tool for tapping into both cultural and material resources as well as expressing oneself, and thus is an important factor through the duration of conflict". Language variation supports different ideas and approaches in such a way that the end result benefits everybody. Now more than ever, there is an even greater need for studies as well as programs oriented around this subject.

In this paper, we have chosen to defend language as a means of blocking conflict, solving problems, and strengthening communities. Knowing more than one language opens doors for those who are studying and those who are employed alike. It is a fact that knowing English is advantageous. Being able to tell one's story as well as express oneself in a language that many people understand is a positive experience for everyone. Learning languages elevates intercultural sensitivity, as well as induces social unity. We also defend that language-learning activities ease the social trauma of students living in a state of migration, and that they benefit them psychologically.

\section{METHOD}

The core of this research is comprised of 83 Iraqi refugee students receiving education from the Ordu Metropolitan Municipality Religious Vocational Middle and High School in the district of Altınordu, Ordu. These students are finishing the remainder of their schooling, and plan to continue onwards with their education.

Table 1 Student profiles

\begin{tabular}{lccc}
\hline Grade & Female & Male & Total \\
\hline 5 & 1 & 2 & 3 \\
6 & 4 & 2 & 6 \\
7 & 4 & 5 & 9 \\
8 & 6 & 1 & 7 \\
9 & 7 & 5 & 12 \\
10 & 4 & 4 & 8 \\
11 & 7 & 5 & 12 \\
12 & 9 & 17 & 26 \\
\hline Total & 42 & 41 & 83 \\
\hline
\end{tabular}


Our group of students consists of 42 female and 41 male students. Of this, 58 students are continuing their high school education, whilst 25 students are continuing their middle school education. The detailed grade/classroom distribution of these students is provided in the table 1 above. All of the subjects are of (Arab) Iraqi origin. Total of $8.4 \%$ are 11 years of age, $6 \%$ are 12 years of age, $6 \%$ are $13,8.4 \%$ are $14,9.6 \%$ are $15,16.9 \%$ are 16 , $10.8 \%$ are $17,19.3 \%$ are $18,7.2 \%$ are 19 , and $7.2 \%$ are 20 years of age. On being asked "Do you know or have you studied a foreign language other than Turkish?": 30 students had answered "English", 3 answered "French", 1 answered "German", 2 answered "other", and 6 had answered "I don't know another language" . Of the male students, 26 had answered "English", 2 "French", 1 "German", 5 "other", and 7 "I don't know another foreign language." As this study indicates, a large majority of the students in this study have some knowledge of English, and a total of 13 students know no other language beyond their mother tongue and Turkish.

The researcher of this paper has 18 years of experience as an English teacher within Turkish National Ministry of Education, as well as five years of international experience as a teacher of Turkish. Between 2015 and 2017, the researcher was the teacher of these classes and had taught these students both Turkish and English at the Ordu Metropolitan Municipality Religious Vocational Middle and High School in the city of Ordu, Turkey.

\section{Purpose, Data Collection ToOl AND Method}

Many of the migrant students chose to remain in the background rather than make friends. The student thus becomes closed off and finds themselves trapped within in an isolated inner world. The aim of this paper is to show what benefits the foreign language training we provide has on institutions, communities, and individuals in order to accelerate guest students' adaptation into the society within which they are living, as well as into education. One of the important aims of this research is to observe how language is used as a tool to support social cohesion, as well as how it is able to help refugees improve their skills to adapt themselves to the social fabric of the host country. We also think that building the capacity of the language teachers in host communities is an important means of preventing future problems.

This paper is also expected to serve as a reference guide for language training programs in multicultural environments as based on the results of this study. What is most important is focusing on meeting the fundamental needs of the students. This entails developing their language skills, followed by improving their relationship with the language as their literacy skills, as well as elevating their sense of belonging within the host country by helping them understand, observe and discover its society, and by deepening their sense of global inclusion (Conteh, 2015).

The students' educational progression was evaluated through classroom observation, interviews, e-mails, telephone conversations, face-to-face discussions, family visits, and casual talks with parents, teachers, and youth, and then outlined as being the sample group. Importance was given to students' feedback, whereupon the researcher used students' opinions as a means for helping resolve the challenges that they individually as well as collectively face. 


\section{DATA ANALYSIS AND RECOMMENDATIONS}

\subsection{Linguistic challenges faced by students and parents}

This section focuses on three points: 1) the role the linguistic challenges faced by refugee students; 2) the linguistic skills of the parents of these students, their views on foreign language training, and the challenges that their language barrier poses; and 3) the role of educators and administrators in resolving these challenges.

Students have in the past helped with the Arabic classes taught at school in question. However, the lack of willingness on the part of Turkish students had yielded this situation fruitless, and had slowed down the establishment of healthy dialogue. As few Turks have any knowledge of colloquial Arabic, the language barrier faced by the students takes top priority in schools, and has a negative impact on their education.

In order for foreign students to integrate into their host country, they should thus learn its language(s). Upon asking the Iraqi students the question "do you feel that learning Turkish is important?" a total of 74 students - 38 female and 36 female answered "yes". In Turkey, the Latin alphabet with a left-to-right writing direction is used. Turkish, which is the language in (official) use, is an agglutinative language and that radically differs from Arabic in terms of its structure.

One aspect that makes the acquisition of Turkish somewhat easier for Arabic speakers is the fact that many words within the Turkish language are of Arabic origin. Pronunciation problems are common to the structure of the alphabet. According to the answers given to the question "Which sounds in the Turkish language are difficult for you to pronounce?" the majority of students struggle with the phonemes "ü̈, "ö", and " $\breve{g} "$. The phoneme they have the least difficulty with is the vowel "o".

Of those struggling to learn Turkish while in high school, male students struggle most with comprehension and writing, whilst female students struggle more the spoken language. It has been observed that during non-class time, female students struggle more with speaking when compared with their male counterparts. This situation changes from grade to grade. For example, high school students struggle more than middle school students. One can assume that due to a difference in age, female middle school students put more effort into being more talkative and communicative, whereas female high school students are shown to shy away from communication due to social factors such as inhibition, being foreign, bias, and culture. Female Iraqi students may shy away from communicating with their Turkish peers. Middle school students do not have this problem due to their being younger in age.

Iraqi students whilst trying to learn Turkish may be mistreated by their peers because of their broken Turkish. The words students have learned may be wrong. Turkish students may intentionally teach them words incorrectly and later use that against them, thus negatively impacting the student. What results is that these students, rather than asking their Turkish-speaking peers about the words they do not understand, they instead choose to ask their fellow Arabic-speaking peers. In turn, such miscommunication problems lead Iraqi students to lose interest in learning Turkish. The reason for this is that Turkish students themselves lack cross-cultural sensitivity. Here, the responsibility falls upon the shoulders of the teacher, whose duty it is to elevate their students' sense of linguistic and cultural awareness. 


\subsubsection{The role of school administrators and parents}

School administrators should provide the necessary support to teachers and to refugees when designing TFL classrooms. The Turkish language classroom should be set up in such a way to prepare students to learn the language. Materials (i.e. posters) to be used as part of lessons should be found, and special libraries should be created. On the matter of language, those who excel in and/or those enrolled in English should be streamed into levelappropriate classes, or else they will lose interest because of repeated material.

The level of language proficiency among school administrators should be increased as well. This is because miscommunication leaves a bitter taste in the mouths of those who experience it. Many students coming from other countries are better able to communicate in a foreign language due to having acquired one through a family trade or through schooling. Students are used to facilitate communication between school administrators and parents. This language use may either be English, Arabic, or Turkish; however students who wind up serving as intermediates or translators become at risk of falling behind in their classes.

The attitudes and behavior of school administrators towards new refugees and their parents is also very important. Administrators and teachers should be informed about and show more care for this matter. When it comes to the subject of language, people on both sides of the fence feel uncomfortable when miscommunication occurs regardless of how much the family wants their child to be educated, or of how much school administrators want to assist families.

Parents tend to attend school less frequently due to a language barrier. The only time they come to school is for parental and health-related permission, report cards, and other necessary paperwork. The communication barrier between parents and school administrators also naturally plays a role in parents not keeping up with their children in terms of monitoring and attendance. Parents' lack of Turkish also poses a problem. This negatively impacts both their children as well as themselves. One sees that mothers who lack Turkish confront the threat of being isolated from society.

A handful of parents and students have requested courses in colloquial Turkish. Courses are in fact being offered by adult/public education centres out of urgency. It is felt that foreign high school students receiving private Turkish lessons also should be able to benefit from such a system.

Sometimes families fail to learn Turkish collectively, whereby parents exclude their children. In order to have these families participate together in such courses, children too need to be involved. Here, students' families participate or are encouraged to participate in some of the language activities. This in turn increases social integration, as well as benefits the social, psychological-mental, and physical well-being of the students. Students thus meet and socialize with different people and, in addition, feel safer in the neighbourhoods within which they are living because of the doors these courses open for them.

\subsection{The role of language programs during displacement}

Because of classroom observation, interviews, telephone conversations, face-to-face discussions, family visits, and causal talks with parents, youth, and teachers, we have witnessed that refugees bring their perspectives, cultures, and languages with them when they leave their homes. They are forced to re-establish themselves in environments that can be totally alien to them. Language helps those who have lived through trauma and who face problems expressing themselves. Language education rescues the student from 
this distress and offers them a safe environment. Lessons heightens the frequency of communication, as well as speeds up community unity.

Due to the trauma that students have lived through, many live in "fight or flight" mode. However, a safe atmosphere had been created because of the variety of language learning activities. We had also observed that performing dialogues, small plays, theatrical sketches, storytelling, duets, various group activities, and the singing of songs, had somewhat lowered this psychological stress. Performing songs learned in a foreign language also contributed to correcting students' pronunciation skills as well as to enhancing their socialization.

Turkish is the medium of education across all public schools in Turkey, whilst English is mandatorily taught from the second grade onwards. Statistically speaking, those in Turkey who know English surpass those who know Arabic. Turkish high school students' level of communication skills in English versus in Arabic is better. Communication skills in both Turkish and English are a problem for many Iraqi students. As the level of English and/or Turkish they have learned in their own countries is limited, they naturally struggle communicating in their new country. The level of English among students prior to leaving their home countries tends to be higher than it is after living in Turkey for a period. These students are slightly better able to establish communication, which is reflected in terms of their social comfort. Those who know English are able to bridge communication between the two groups. Many students and parents feel that their children's learning of English is a one-way ticket out the crisis within which they are caught in. Knowing English will make their children's lives significantly easier as it means that they either will have to defend their rights internationally, or that they may be forced yet again to change countries. For this reason, they encourage their children to take English classes.

Bettelheim has suggested that storytelling is one means of relief from trauma that yields positive results (Bettelheim, 2010). This is because storytelling is done in the third person, and because the language student recovers psychologically through the relaxation and selfconfidence formed through storytelling. Language education planning for refugees should be done in order to integrate students. Non-violent content was consciously selected for our lessons. Storytelling was used involving a handful of voluntary students during English classes. Local school students were taught how to form empathy through story telling competitions. Those who knew English had expressed themselves better. Teachers at times had no concept of the histories of their students. Moreover, the telling of the stories had given the teachers the chance to get to know their students better.

Teachers can psychologically help students through unique, thought-provoking, productive and creative activities such as theatre. In essence, students' inner worlds are discovered through these activities (Sutherland, 1997). In order to further socialize Turkish and Iraqi students, the two groups were assigned to work on theatre exercises together, which also contributed to sharpening their language skills. Puppet theatre was beneficial for very young students. The number of teachers in urban areas who engage in these activities is dropping. It is believed that some Iraqi students are able to acquire Turkish without having received lessons. This method in the field of language teaching and acquisition method is known by Krashen as the "Natural Approach". Krashen suggests that language learners learn language naturally through interaction rather than consciously focusing on the language they are learning (Krashen, 1981, 1982).

Unconventional and advanced creative language teaching techniques predictably had an even greater influence on the dialogues we had with refugee students. Freire's Critical 
Pedagogy method provides positive results when it comes to language teaching reaching out to students (Freire, 1970). Critical Pedagogy is an approach that discusses problems, questions reasoning, puts forward ideas, and solves problems. Honing students' abilities to think, be creative, express opinions, and solve problems naturally steers them away from shyness, as well as makes them more active. This approach is built more upon social and educational equality. This is a theory that has students embrace the problems that they encounter through sociological and political means, and grants them a sense of freedom (McLaren, 1993; Glenn, 2002; Kincheloe, 2004; McLaren, 1998; Freire, 2010).

\subsubsection{The benefits that career-oriented language training poses for refugees during displacement}

There are fewer students enrolled in high school than those enrolled in elementary or middle school. The reason for this is that their motivation is to learn enough Turkish to be able to carry on with their lives and to establish work in order to earn pocket or bread money. Students who express little interest in continuing their high school education, which especially holds true for males, want to study a language for professional reasons. These students want to set up their own businesses or to advance in a trade/career that is suited to their abilities. Others aim to specialize in the trades they had learned prior to coming to Turkey.

Providing the students with language courses that are industry-specific presents them with work opportunities as well as with the strength to get through life. In the case of this study, it appears that professional language courses provided students positive results. In terms of their trades, most were engaged in areas such as computer technology, tailoring, barbering, beauty, electrical engineering and electronics, cooking, cake making, needlecrafts, table waiting, and hospitality. There were also benefits in providing lessons on the language of the workplace, such as application letters, conducting interviews, and filling out forms. The students were also motivated to increase their language levels by doing medical, legal, and academic translations. Such programs appear to encourage the participation of female students. Forming a group of parents who were in need of job-oriented English and/or Turkish lessons was a great means of increasing their language proficiency. The increase in a family's income is reflected in the motivation levels of students. May states that a welldesigned language program no doubt positively influences cultural, generational, and familial harmony and relationships (May, 2012).

Students and parents who have been injured and are receiving treatment are eager to learn medical language as they want to describe their problems and to speed up the treatment process. Students who have good grasp of a foreign language override this issue in that their knowledge makes it easier for them to obtain prescriptions and to express what is wrong. When they go to hospital in order to receive treatment, having knowledge of hospital language aids them in being able to receive help. Some students wanted to improve their language skills in order to be able to obtain medicine from a pharmacist for an ill family member.

As we have observed, helping refugee students to break down the language barrier automatically enables them to feel protected and safe. The students, in knowing and learning the language of their host country helps them to feel more self-confident, helps them more easily establish communication with their peers, helps them earn better education, and have broader employment opportunities. These will withdraw the students 
from their loneliness, remove the distance between them and society, enable healthy dialogue, and speed up the process of social integration. This approach at the same time can serve as a guide for language planners.

\section{CONCLUSION AND RECOMMENDATIONS}

Students need support when it comes to integration into their school environments. During this process, doing more engaging activities such as creating an environment that encourages friendship building rather than imposing responsibilities yields more positive results. Furthermore, groundwork is being laid in order for students to believe in their permanence. Over the course of the running and planning activities for refugee students, volunteers who are experienced and/or who have a multicultural background should be invited into the class and interact with the students.

The teacher upon helping students should never forget that the person opposite them is an individual, and that they can reach out to that individual through body language when words fail. As students gain courage, they want to be able to ask the teacher or have the teacher repeat what they do not understand. Students prefer skipping school due to their not being accepted within the social environment the teacher has created for the student. This is a distinct behaviour on the part of the student who occupies themselves with other things during class time because they dislike how they are being treated in class. Teachers are eager but negatively impacted by these actions because their students are aware that they are treated as migrants or refugees rather than as individuals.

When it comes to the subject of the process of intercultural sensitivity, it is evident that teachers need to be trained in this matter, that the national education system needs to be made aware of the situation, that classroom materials need to aid cross-cultural sensitivity, and that multi-cultural classroom environments need to mindfully support students' learning. The teacher should pay attention to social harmony and understanding, student-inclusive pedagogical approaches, student-centred multilingual learning, and to student-teacher harmony insofar that these will be of benefit to the students. These matters should be integrated into the curriculum by the teacher and should not be overlooked during the evaluation process.

It is a fact that there are gaps in the Turkish education system when it comes to managing multicultural classrooms. Higher-level educators should be tasked with pedagogic formation oriented around such classrooms. While many students enjoy the environment that they find themselves in, it is a fact that those same students misbehave. At the same time, one has to adapt themselves to how one is to act in school given that students lack language skills, and that their sense of discipline is different given that they are coming from a different cultural context. This has a negative effect on classroom discipline. This can also influence Turkish students when it comes to tardiness and attendance. Students' beliefs that their education is temporary can quite naturally lower their demonstration of academic success. The additional time needed to accommodate these students can also disturb the class. School administrators and teachers resolve issues through preventative and restorative means. The teacher should have methods in place that reduce stress as they too can negatively affect their students. Therefore, teachers working in both state and private schools as well as for non-governmental organizations should be informed about this matter. Certificate-based programs should also be established and participation encouraged. 
There is no doubt that if teachers view refugee students as but mere guests is a negative approach. In order to eliminate this, teachers should be briefed on how to teach those students more inclusively. This at the same time would increase their methodological experience.

All-inclusive support for English language instruction in schools and institutions naturally provides groups with the opportunity to communicate with each other, to be able to satisfy themselves, and to increase their life skills. Students who focus more on language rather than on communication will fall short when it comes to actual communication. Another problem is that Turkish teachers themselves lack any considerable proficiency in a second foreign language. Teachers who teach English as a foreign language in multicultural classrooms should understand cultural, historical, and perceptual diversity, and should know how they approach that. The use of the CLIL (Content and Language Integrated Learning) approach in language teaching would be of benefit as this method encourages full language immersion (Lightbown \& Spada, 2006; Wesche \& Skehan, 2002).

School teachers do not go above and beyond in terms of lesson planning. Teachers who are to teach these students need themselves to receive on-the-job training. The teaching of Turkish as a foreign language in Turkey has gained wind over the past several years, however a shortage of specialist teachers remains. Teachers in this field tend to work abroad via the "Yunus Emre Institute" and "Yurtdışı Akraba Topluluğu" (Turkish Diaspora Association). In larger Turkish cities, the number of TFL teachers is higher. This number should be increased by increasing the number of certificate programs in smaller cities.

Cultural diversity enriches the classroom. The struggles that refugee students have lived through prior to coming to Turkey can serve as an initiating point for Turkish students in developing empathy and understanding. Resolving the linguistic divide can eliminate bias and polarization. The teacher should not feel that they are doing their job simply out of duty, and they should make their non-Turkish students feel welcomed by society. Students may feel themselves to be unaccepted when teachers themselves seem reluctant, which in turn adds to the many other challenges that rest upon students' shoulders.

\section{REFERENCES}

Bettelheim, B. (2010). The uses of enchantment: The meaning and importance of fairy tales. Vintage Books

Conteh, J. (2015). The EAL teaching book: Promoting success for multilingual learners.in primary and secondary schools, London: Sage

Freire, P (1970). Pedagogy of the Oppressed. Continuum: New York

Freire, P (2010). Ezilenlerin Pedagojisi, (Trsn. D. Hattatoğlu ve E. Özbek), Ayrıntı: İstanbul

Glenn, B. Cathy (2002). "Critical Rhetoric and Pedagogy: Considering Student-Centered Dialogue”, Radical Pedagogy, 4(1).

Krashen, S. (1981). Second Language Acquisition and Second Language Learning. Oxford: Pergamon Press.

Krashen, S. (1982). Newmark's "Ignorance Hypothesis" and current second language acquisition theory. Unpublished manuscript.

Kincheloe, L. Joe (2004). Critical Pedagogy Primer, New York: Peter Lang Publishing Inc.

Luthar, SS and Cicchetti, D (2000) The construct of resilience: Implications for interventions and social policies. Development and Psychopathology, 12, 857-885 
Lightbown, P. M., ve Spada, N. (2006). How languages are learned (3.Edt.). Oxford: Oxford University Press.

Lynnette, R. (2001). Corporal punishment in American public schools and the Rights of the Child. $J$ Law and Education, 30, 554-563

May, S (2012) Language and minority rights: Ethnicity, nationalism and the politics of language. Routledge: New York

McLaren, Peter (1993). Schooling as a Ritual Performance: Towards a Political Economy of Educational Symbols and Gestures, New York: Routledge

McLaren, Peter (1998). Life in Schools: An Introduction to Critical Pedagogy in the Foundations of Education, New York: Longman

Sutherland, M (1997). Using Storytelling as a Therapeutic Tool with Children. Speechmark Publishing

Wesche, M.B., and Skehan, P. (2002). Communicative, task-based, and content-based language instruction. R. B. Kaplan (Haz.), The Oxford handbook of applied linguistics (ss. 227-228). Oxford, UK: Oxford University Press

UNHCR. (2016). UNHCR Syria regional refugee response. http://data.unhcr.org/ syrianrefugees/regional.php, accessed 23.04.2016

3RP regional refugee \& resilience plan 2015-2016 in response to the Syria crisis. UNHCR and UNDP, 2015. (accessed Jan 28, 2015) 